\title{
NOTE ON THE OCCURRENCE OF MALARIAL FEVER IN PLACES USUALLY FREE FROM ANOPHELES.
}

\author{
BY JOHN CROPPER, M.A., M.D.
}

Tне above heading sufficiently indicates a difficulty which has doubtless often occurred to those who have studied the subject of the agency of Anopheles in the causation of malaria. In some cases this difficulty has seemed so formidable that disbelief in any such agency has been boldly professed. The following observations, most of which I owe to the kindness of Dr Gould, who succeeded me at Acre in Palestine, will help to explain the occurrence of malaria at places where there would seem to be little or no breeding-ground for Anopheles, and prolonged observation by residents has not revealed the presence of the perfect insect.

I. As mentioned in a former paper in this Journal (Vol. II. p. 47, 1902) on the Geographical Distribution of Malaria in Upper Palestine, though resident for some years in the town of Acre, $I$ had never been able to find a single specimen of Anopheles. This year (1903), Dr Gould had two patients-boys of his native dispenser-ill with malaria. The parasite at various stages was clearly demonstrated in their blood, and the facts allowed of only one interpretation, viz. that in at least one case the disease had been caught in the town. Anopheles mosquitoes were found in the room in which they lived. It is uncertain where these were bred, but last winter was exceptionally wet, and the water covered the plain within less than half-a-mile from the town, near the wall of which the house is situate. As I mentioned in the paper just referred to malaria occurs in Acre itself, but comparatively rarely, though common enough a mile away.

II. At Shefa Amr, 3 hours from Acre, situated on low lying chalk hills, well raised above the plain and within reach of no running water, except after heavy rain, two English ladies had malaria, one after the other. Though imagines of Anopheles were not found, yet in the water 
from an open cistern, brought for washing, larvae of Anopheles were found quite recently by $\mathrm{Dr}$ Gould.

I had the privilege of Dr Gould's help when in the country two years ago, and know how well acquainted he is with the larvae of Anopheles.

III. The third place to be mentioned is Nablous, where I spent some months this summer. In $1901 \mathrm{Dr}$ Gould found Anopheles larvae in a shallow cistern used to catch the rain water before it is allowed to run into the main cistern of the parsonage belonging to the Church Missionary Society. This year an examination of several of the open cisterns in houses in the town to which I went to treat patients, gave a negative result, nor was I more successful outside the town. On examination of the above-named cistern however I succeeded in getting 9 Anopheles without special apparatus, the vast majority of the species being Culex or Stegomyia fasciata.

Cases of malaria are quite well known in the town but are very infrequent considering the large number of outpatients treated at the Hospital. Splenic enlargement is also rare. Amongst the English ladies working in the Mission a few attacks of malaria have occurred, their house being but a few yards away. More recently two Anopheles larvae were found at the new Hospital, with many Culex.

Within 4 hours of Nablous to the east is the Ghor or Jordan Valley, notorious for its unbealthiness; and within 9 hours is Beisân, than which few places are more deadly. Patients and visitors to the town often come in from these parts, and thus the malarial parasite, which would otherwise die out, is furnished. So it is probably with many, if not all places in the Tropics not essentially malarions, i.e. not furnished with an abundant supply of Anopheles. 